\title{
AUTONOMIA, BIOÉTICA E DIREITOS DA PERSONALIDADE
}

Daisy Gogliano(*)

\section{AUTONOMIA}

Em sentindo amplo, a palavra autonomia significa a condição de uma pessoa, ou de um grupo de pessoas, se determinar por si mesmo, ou seja, de se conduzir por suas próprias leis, por auto-regulamentaçăo ou auto-regramento.

Por exemplo, na Biologia considera-se autônomo o animal capaż de levar uma existéncia independente e propria, em contraposiçăo ao parasitismo, sem que implique uma independência total e absoluta em face do meio em que vive e do qual subsiste.

Felipe Rocha, professor de filosofia de Braga da Universidade Catolica Portuguesa, em interessante artigo "Educar para a Liberdade e Autonomia"(1), tece importantes consideraçðes a respeito do tema em seus aspectos filosoficos, observando que "a autonomia tem amplos e profundos laços com a liberdade. Etimologicamente (autós = próprio; nomos = regra, lei), significa ela a condiçăo de uma pessoa, grupo ou coletividade maior que determinem, eles proprios, as regras a que se submetem".

No campo ético-moral, a autonomia "designa, por um lado, o controle racional das pulsós instintivas (liberdade moral) e, por outro lado, a não aceitaçáo, sem consideraçato próvia, de regras de conduta provenientes de uma entidade eterna"(2). Em suma, no seu entender, "liberdade e autonomia săo caracteristicas do homem concreto e estâo a serviço da realizaçăo dele. Tiradas deste contexto, transformam-se em mitos, como aconteceu em séculos passados!"(3)

O fato é que esse mito (ético-moral), que teve o seu apogeu com Kant (1724-1804), ganhou relevo ao ser erigido como a essência da vontade, a

( ${ }^{\star}$ Professora Doutora da Faculdade de Direito da Universidade de São Paulo, doutora em direito.

(1) Felipe Rocha, "Revista Portuguesa de Filosofia", 1993, n. 49, p. 104.

(2) Idem, Ibidem.

(3) Idem, Ibidem. 
qual deve atuar com total independência de qualquer consideração alheia à razão pura. Na teoria da autonomia da vontade, esta só será autônoma na medida em que se determinar pela sua essência, pela própria lei que contém em si, sem qualquer relação com os objetos a que se dirige. A vontade se legitima na razão pura, na abstração, no racionalismo que tudo pode e tudo governa. É o ser racional bastando-se a si próprio.

A filosofia de Kant penetrou em todos os ramos do conhecimento, influenciando, igualmente o Direito. O ilustre Professor Francisco dos Santos Amaral Neto, em alentado e profundo estudo em homenagem ao Professor Doutor Ferrer-Correia, publicado no Boletim da Faculdade de Direito da Universidade de Coimbra ${ }^{(4)}$, demonstra, com a clareza que lhe é peculiar, que 0 dogma da vontade, assentado no individualismo e no contratualismo, "resultante das concepções jusnaturalista e iluminista que tão bem se positivaram no Código de Napoleão e no B.G.B., nos quais a pessoa humana, com sua liberdade e autonomia, era o centro por excelência do universo jurídico, e 0 direito civil, 'a garantia dos fins individuais relativos à família e aos bens', foi-se reduzindo gradativamente a partir do começo do século e, acentuadamente, com a Segunda Guerra Mundial, mercê duma progressiva intervenção do Estado, que limita a autonomia da vontade, quando não a elimina totalmente, às relações de microecoṇomia".

Francisco dos Santos Amaral Neto não deixa de chamar a atenção sobre as diferenças entre a vontade psicológica e a vontade jurídica, sobre a autonomia da vontade e autonomia privada, lembrando que a "vontade psicológica e a vontade jurídica não são, porém, coincidentes. Enquanto que a psicologia conhece a vontade como 'tipo especial de tendência psíquica, associada a representação consciente de um fim e de meios eficientes para realizá-lo', estudando-a no campo do ser, o direito aprecia-a no campo do dever-ser, no campo da dogmática jurídica, reconhecendo-a como fator de eficácia jurídica nos limites e na forma estabelecida pelo sistema normativo"(5).

E acrescenta: "A esfera de liberdade de que o agente dispõe no âmbito do direito privado chama-se autonomia, direito de reger-se por suas próprias leis. A autonomia da vontade é, portanto, o princípio de direito privado pelo qual $o$ agente tem a possibilidade de praticar um ato jurídico, determinandoIhe o conteúdo, a forma e os efeitos. Seu campo de aplicação é, por excelência, o direito obrigacional, aquele em que 0 agente pode dispor como the aprouver, salvo disposição cogente em contrário. $E$ quando nos referimos especificamente ao poder que o particular tem de estabelecer as regras jurídicas de seu próprio comportamento, dizemos, em vez de autonomia da vontade, autonomia privada; autonomia da vontade como manifestação de liber-

(4) Francisco dos Santos Amaral Neto, in Estudos em Homenagem ao Prof. Doutor Ferrer-Correia, Boletim da Faculdade de Direito da Universidade de Coimbra, Coimbra, 1989, p. 11.

(5) Idem, ibidem. 
dade individual no campo psicológico, e autonomia privada, o poder de criar, nos limites da lei, normas jurídicas"(6).

Emilio Betti considera a autonomia privada como um "fenômeno logicamente correlativo ao da existência das esferas individuais de cada um"(7), como gênese dos negócios jurídicos, ou seja, a regulação de interesses recíprocos no meio social, interesses esses correlacionados, impulsionados pela troca constante de bens e serviços economicamente apreciáveis. Nas palavras de Bettri "Os próprios particulares, nas suas relações reciprocas, provêm à satisfação das suas necessidades de acordo com a sua livre apreciação, por meio da permuta de bens ou de serviços, da associação de forças, da prestação de trabalho, do empréstimo ou da colocação de capitais comum, etc. A iniciativa privada 'é o aparelho motor de qualquer consciente regulamento recíproco de interesses privados". Por mais rudimentar que seja uma determinada civilização, a troca de bens e serviços visando escopos comuns e recíprocos são desenvolvidos por regras sociais próprias e costumeiras, com base nessa iniciativa privada e particular, "onde a sanção do direito apresenta-se como qualquer coisa acrescentada e logicamente posterior: mais precisamente, como um reconhecimento de autonomia"(8).

Os negócios jurídicos têm a sua gênese nesses "atos por meio dos quais os particulares procuram satisfazer a necessidade de regular por si mesmos os seus interesses nas relações recíprocas: atos de auto-determinação, de auto-regulamentação dos seus próprios interesses. A auto-regulamentação que a consciência social já considera vinculativa para as partes, mesmo antes do ato ser elevado à dignidade de negócio jurídico: quer dizer, ele é considerado não como um programa puro e simples, a que as partes podem, livremente, ater-se ou não (tal como poderia acontecer com o propósito individual, formado no intimo da consciência), mas como um critério vinculante, como uma regra de conduta que tem de ser observada e que, no caso de inobservância, é acompanhada na vida social por sanções mais ou menos enérgicas e seguras, tanto de caráter específico (ex. medidas de retorsão e de auto-tutela) como de caráter genérico (ex. perda ou diminuição do crédito social, com a conseqüente impossibilidade, ou dificuldade, de realizar novos negócios jurídicos)"(9).

Importa observar que os fatos da vida social a que o direito agasalha são, portanto, vinculantes pela sua necessidade prática, devem ter relevância social, cabendo ao direito impor-lhe condições e limites a esse reconhecimento(10). Em suma, nas palavras de Emílio Betti, a "autonomia privada

(6) Francisco S. Amaral Neto, "Estudos..." cit., p. 12.

(7) Emilio Betti, "Teoria General del Negozio Gluridico", $2^{\natural}$ ed., trad. Fernando de Miranda, Coimbra, UTET, 1969, t. I, p. 88.

(8) Emilio Betti, ob. cit., p. 92.

(9) Idem. Ibidem.

(10) Emilio Betti, ob. cit., p. 106. Năo se pode confundir a autonomia privada com a autonomia individual, onde cada um é livre para agir de acordo com a sua consciência, desde que sofra as consequeencias de sua conduta, sejam ou não vantajosas ou onerosas. $O$ dogma da vontade, mera qualificaçāo formal, não apreende a essência da autonomia privada como fato social. 
tem, portanto, caracteres próprios, claros $\theta$ inconfundíveis com os de qualquer outra autonomia, como atividade e postostas, criadora, modificadora ou extintora de relaçóes juridicas entre particulares: relaçóes cuja vida e vicissitudes săo antecipadamente disciplinadas por normas juridicas preexistentes"(11).

Em suma, a autonomia privada como auto-regumentação dos próprios interesses, reconhecida como fonte de normas jurídicas, mutável variável como todo fato social, sofreu profundas transformações ao longo deste século, onde o liberalismo do século XIX cedeu lugar ao intervencionismo estatal, ao dirigismo contratual. Pense-se, v.g., nas relaçóes jurídicas que envolvem a prestação de serviços de saúde, na adesăo a "Planos de Saúde", os quais não permaneceram muito tempo à mercé da iniciativa privada, fazendo-se cada vez mais presente a intervenção do Estado na regulação de interesses privados, impondo normas cogentes, estabelecendo limites na sua atuação, rompendo com o Individualismo calcado nas concepçóes do jusnaturalismo e do lluminismo, formas extremadas, como todos os "ismos", que influenciaram as codificações modernas, notadamente na França e na Alemanha. Os institutos jurídicos passaram a exercer funçăo economico-social, dando lugar ao coletivismo e hoje à denominada "globalização", impondo-se cada vez mais a realização de uma justiça social, concreta e verdadeira.

O fato é que a autonomia em sentido filosófico năo se confunde com o jurídico, embora as idéias filosóficas influenciem de algum modo as concepções jurídicas. A autonomia como fundamento da ética, que pressupõe a independência do ser humano na valoraçăo dos problemas morais ${ }^{(12)}$, como faculdade de autodeterminação, não significa autonomia normativa calcada no poder de se dar as próprias normas, em oposiçáo a heteronomia que implica sujeiçăo ao poder de outrem.

\section{AUTONOMIA NA BIOÉTICA}

De maneira uníssona, a autonomia tem sido tratada na Bioética como o seu princípio informador ou o seu fundamento. Nas questões que envolvem os atos de disposição do próprio corpo na Medicina firmou-se o conceito largamente difundido que todo paciente tem o direito insito de proteger a sua própria inviolabilidade física e psíquica e o direito de, por auto-determi-

(11) Emilio Betti, "Teoria..." cit., p. 98.

(12) Cl. José Casalta Nabais, "A autonomia local", in Estudos em homenagem ao Prof. Doutor Afonso Rodrigues Queirób, Coimbra, Boletim de Faculdade de Direito da Universidade de Coimbra, 1993. Observa o autor que no campo filosófico a autonomia da vontade, base da ética Kantiana, implica atuar com total independéncia de qualquer consideração alheia à razão pura. Vontade autónoma é aquela que se determina pela sua própria esséncia. Entre os estoícos, "sofos" é o homem perfeito que nāo necessita sujeitar-se às leis alheias, da "polis". Em suma, o termo autonomia é polissêmico ao traduzir os mais diversos fenómenos, v. g., autonomia de vóo, autonomia local, autonomia estadual, autonomia normativa, etc. "A vontade será autónoma na medida em que se determine pela própria lei que contém em si". 
nação, conduzir o que pode ser feito com o seu próprio corpo, incluindo os atos de disposição tanto para depois da morte como em vida.

Com base nessa premissa, de que todo homem é autônomo, facultase a recusa de tratamento médico em face do "consentimento-informado", ou seja, do "consentimento-esclarecido" calcado no dever do médico de informar o paciente sobre os procedimentos terapêuticos ministrados em seu corpo.

Essa autonomia advém do fato de que todo homem é um ser racional, com capacidade de entender e de querer como todo homem "normal", dotado de razão e de consciéncia.

Assim, a faculdade de querer, de impor a sua autonomia reside na "racionalidade" do próprio homem que pode deliberar sobre a recusa ou aceitação de tratamento médico, experimentação humana e demais atos de disposição do próprio corpo, pelo simples fato de ser "um ser racional", dotado de razäo. A sua liberdade de escolha a sua auto-responsabilidade conduzem ao respeito a dignidade humana.

A tal ponto a autonomia tem sido decantada que os autores especialistas em Biótica, denominados "bioeticistas", consideram que o paciente, dotado de razão, deve e pode escolher, com base na "lei moral", o tipo e a forma de tratamento que mais lhe convém, ou seja, que mais the apetece, mesmo contra a sua saúde, desde que a sua capacidade de decidir não esteja afetada ${ }^{(13)}$.

Essa idéia puramente racional de que todo homem pode deve agir dentro dos limites impostos pela lei moral, afastando assim toda e qualquer submissão ao ato médico, desde que tenha higidez mental, com capacidade de entender e de querer, justamente por ser pessoa dotada de razăo, vem sendo largamente difundida entre os especialistas da matéria, dentro do mesmo paradigma - o racionalismo - naquilo que envolve questões de vida, saúde, morte e todos os demais atos de disposição do próprio corpo.

Voltando-se contra os velhos padrões da Medicina, considerada "paternalista" na relação médico-paciente, em que o doente, sem questionar, submetie-se a toda e qualquer prática médica sem qualquer direito de ser informado sobre os atos médicos a serem ministrados em seu próprio corpo, a Bioética propõe-se, principalmente diante das novas tecnologias médicas, tais como inseminação artificial, transplantes de órgãos e tecidos humanos, fertilização in vitro, manutenção de respiraçãocardio assistida, etc., a resgatar, na modernidade, os valores da pessoa humana, o respeito a

(13) Vide: Marcos de Almeida, Daniel Romero Muñoz, Brasilia, Revista Bioética, CFM, 1994, v. 2 , n. 2, p. 148: ... autonomia é a capacidade de pensar, decidir e agir, com base em tal pensamento $\theta$ decisāo, de modo livre e independente. Na esfera da açāo, é importante distinguir, por um lado, liberdade, isenção, licença, ou simplesmente "fazer o que lhe der na telha" e, por outro lado, agir autonomamente, que também pode ser fazer o que se quer, mas baseado em deliberação racional. 
sua dignidade, mostrando, assim, que o médico não é dono do corpo do paciente.

O que queremos mostrar no presente estudo é que tais questões, que hoje, na sua medida, se apresentam como "novidade" do final do século XX, há longos e longos anos, precisamente no seculo $\mathrm{XV}$, foram disputadas sob a égide do humanismo jurídico que influenciaram os "Comentadores" do Direito Romano, contrapondo-se a velha escolástica, a orientação eminentemente teológica dada aos estudos jurídicos, ou seja, promovendo uma reelaboração científico-literária do direito, com a Escola dos Pós-Glosadores.

\section{NOTÍCIA HISTÓRICA DOS DIREITOS DA PERSONALIDADE}

Os direitos da personalidade, direitos personalíssimos ou direitos privados da personalidade realçam o seu aspecto privado ou particular em contraposição ao seu aspecto público, muitos dos quais são elevados a categoria de direitos fundamentais ou garantias individuais no âmbito constitucional, tais como o direito à vida, à integridade corporal, à integridade psíquica, intelectual, honra, nome, imagem, recato, intimidade, etc., considerados, também, direitos da pessoa humana, como direitos subjetivos (facultas agendi), vale dizer, nas palavras de Jean Dabin: "a prerrogativa concedida a uma pessoa pelo direito objetivo e assegurada pelos meios de direito para dispor, como senhor, de um bem que se reconhece pertencer-lhe, ou ser-lhe devido". Tais bens e valores não se limitam a coisas exteriores, porque também compreendem, e de modo mais próximo, os bens ou valores inerentes à pessoa física, como: a vida, a integridade do corpo, as liberdades, etc. Sujeito de direito, para Jean Dabin, "não é aquele que quer, nem aquele que sabe, nem aquele que desfruta, nem aquele que age, nem aquele que sofre; é aquele que tem como seu algum bem. $O$ direito subjetivo se traduz em um ter que pode, aliás, como direito, recair sobre o ser, ou sobre as faculdades de agir do próprio titular"(14).

Com respaldo nessas premissas, conceituamos direitos privados da personalidade como os direitos subjetivos particulares, que consistem nas prerrogativas concedidas a uma pessoa pelo sistema jurídico e assegurada pelos meios de direito, para fruir e dispor, como senhor, dos atributos essências da sua própria personalidade, de seus aspectos, emanações prolongamentos, como fundamento natural da existência e liberdade, pela necessidade da preservação e resguardo da integridade física, psíquica, moral e intelectual do ser humano, no seu desenvolvimento(15).

(14) Jean Dabin, "El derecho subjetivo", trad. Francisco Javier Osset, Madrid, Rev. de Derecho Frivado, 1955, p. 100.

(15) Daisy Gogliano, "Direitos privados da personalidade", São Paulo, dissertaçāo de mestrado na FADUST, 1982. 
Os direitos privados da personalidade apresentam a característica de serem absolutos, irrenunciáveis, essenciais, não-pecuniários, intransmissiveis e imprescritiveis nas suas manifestações plúrimas, como atributos da própria personalidade; não só aquilo que a pessoa tem, mas naquilo que ela $e ́$, concebendo a pessoa humana na sua mais alta expressão, não meramente como ser racional. Absolutos, não pelo fato de a pessoa ser "autônoma", mas no sentido de sua oponibilidade erga omnes, que devem respeitar de acordo com o Direito posto enquanto norma.

Essa categoria de direitos firmou-se principalmente na Alemanha, cujo expoente da escola do Usus modernus foi Samuel Strick (morto em 1710, que ensinou em Leipzig) ${ }^{(16)}$. Outro expoente foi Donellus (Hugo Doneau) que escreveu monumental obra "Comentariorum Juris Civilis Libri", trazendo a lume a concepção de direito subjetivo, a facultas agendi, o poder de agir de acordo com a norma jurídica (e não de acordo com a razão pura), estabelecendo as esferas em que a pessoa exerce o seu domínio e poder (potestas), admitindo duas modalidades de nostrum, conforme desenvolvido mais tarde por Savigny. in persona cujus e in rebus externis. A primeira diz respeito a própria pessoa e compreende: vita, incolumitas corporis e libertas existimatio; onde a proteção da relação de direito com o próprio corpo estava ligada a idéia de um direito de propriedade.

Por sua vez, Samuel Strick, que nos legou expressiva obra "Dissertationum Juridicarum Francofurtensium", discorre em longas páginas sobre o jus hominis in se ispum, ou seja, o direito do homem sobre si mesmo, justamente por ser livre ${ }^{(17)}$.

Tais considerações históricas, com base nas fontes do Direito Canônico, foram estudas com profundidade e particular proficiência pelo insigne professor argentino Santos Cifuentes, ao tratar das origens dos direitos da personalidade, dos direitos da pessoa humana ou direitos personalíssimos ${ }^{(18)}$.

Em sua "Dissertationum" do século XVII, publicada no "Tractatus" de Toledo, em 4 de fevereiro de 1675, que resultou de uma polêmica havida com um cavaleiro da Pomerânia, Casimiro de Osten, sobre os direitos do homem sobre si mesmo, Samuel Strick dedica todo um terceiro capitulo de sua obra ao direito à vida - De jure hominis in vitam - discorrendo sobre a legítima defesa e o estado de necessidade, além de questões relativas ao ato de dispor da própria vida. O quarto capítulo, por sua vez, - De jure hominis in corpus - embora na ausência de sistematização, cuida dos atos

(16) Molitor-Scholosser, "Perfiles de la nueva historia del derecho privado", trad. Angel Martinez Sarrión, Barcelona, Bosch, 1980.

(17) Samuel Strick, J. U. D., "Dissertationum juridicarum franco furtensium", Dusputat XV, 1975, pp. 401/431, in Daisy Gogliano, "Direitos Privados..." cit., pp. 79 e ss.

(18) Santos Cifuentes, "Los derechos personalisimos", Buenos Aires, Lerner, 1974, pp. 27/28. 
de disposição do próprio corpo, da recusa de medicamentos, da situação do eunuco, da perda das partes do corpo e do tratamento médico.

Como tais questões foram levantadas à época do Direito Canônico, justamente sobre o domínio da Igreja, no apogeu do Humanismo jurídico, em que as idéias cristãs de liberdade e dignidade eram vistas como propriedades e faculdades concedidas por Deus, onde a alma, o corpo e a vida pertencem a Deus ou aos poderes que dele derivam: a Igreja e o Estado (o Príncipe), delinea-se com fundamento na liberdade o germe dos denominados "direitos da personalidade", que teriam o seu apogeu no século XIX.

Outro precursor da teoria dos direitos da personalidade, segundo nos informa Santos Cifuentes, foi Balthassare Gomezio de Amesqua ou Baltasar Gomes de Amesqua, nascido na Espanha, em Toledo, e que fez a sua carreira na Itália. Em 1609 publicou uma extensa monografia sobre a potestas in se ipsum, ou seja, o ius in se ipsum escrita em latim, com o nome de "Tractatus de potestae in se ipsum". Conta com 480 páginas e se divide em duas partes, cada uma com 24 capítulos. A primeira trata das questões mais gerais e a segunda sobre numerosas aplicações ${ }^{(19)}$.

Infelizmente, não pudemos ter acesso a obra de Amesqua e, com isso, limitamo-nos aos estudos e as informações dadas por Santos Cifuentes, que se revela o único especialista na matéria a cuidar do aspecto histórico dos direitos da personalidade, com riqueza de detalhes, enfeixados por observações e análise cuidadosa, não obstante tenhamos conhecimento de outras obras anteriormente publicadas sobre a evolução histórica desses direitos, principalmente na Itália e na Alemanha ${ }^{(20)}$.

Comparando o estudo de Stryck com as informações que revelam conteúdo a forma da obra de Amesqua, constatamos que esta se revela bem mais aberta e liberal para a sua época, conforme se depreende da exposição feita por Santos Cifuentes; "Después de exponer la opinión común de que el de toda potestad sobre sí mesmo, sostuvo lo contario: 'ya por lei de la naturaleza, el hombre carece por los preceptos de los derechos civil, canónico y regio, todo hombre tiene una potestas in se ipsum, en los límites estabelecidos por la ley'. O sea, el derecho de hacer de sí mesmo lo que quiera, salvo to prohibido por aquélla. Era el jus in se ipsum. La obra gira sobre dicha premisa $y$, en particular, se detiene en los limites de la potestad sobre la vida, cuerpo y fama, y las consecuencias que derivan de dicha potestad"(21).

Em suma, na descrição feita por Cifuentes, a obra de Amesqua se ocupa, sem qualquer sistematização, sobre os vários aspectos dos atos de disposição do próprio corpo, merecendo especial relevo os seguintes tópi-

(19) Santos Cifuentes, "Los derechos..." cit., p. 26.

(20) Daisy Gogliano, "Direitos Privados..." cit., p. 83.

(21) Santos Cifuentes, "Los Derechos..." cit., p. 26. 
cos: o suicídio, a automutilação, a proteção da vida, a cirurgia, a anatomia, as penas corporais, as torturas, os pactos sobre as penas corporais e outros assuntos de interesse de cada um e da sociedade.

Amesqua levanta questões importantes, desenvolvendo os seguintes temas por capítulos, como diz Cifuentes: I) os princípios gerais sobre o dano ao corpo, e os perigos, tendo em conta os interesses de cada um e da sociedade; II) os atos positivos e negativos para a salvação do Estado; III) pelo Rei, parentes e amigos; IV) pela saúde espiritual do próximo; V) defesa dos bens temporais e da honra; VI) sobre se é lícito abster-se de comer; VII) recusar a medicina; VIII) sobre se se pode desejar a morte; e entregar-se voluntariamente aos ministros da justiça; o problema dos espetáculos de perigo, etc.

Não se pode deixar de reconhecer a magna importância da obra de Amesqua, escrita nos albores do século XVII, justamente sobre "questões de vida", sobre os atos de disposição do próprio corpo, sobre a potestas in se ipsum nos limites estabelecidos pela lei, e, acima de tudo, pela lei da natureza, sob os preceitos de direito civil, canônico e régio. Tal "potestas", como se vê nas palavras de Amesqua, não deriva da razão pura, do imperativo categórico, da autonomia individual em conformidade com a razão universal abstrata e eidética, no mito Kantiano.

Esboçadas as origens dos direitos da personalidade, em breves pinceladas, dadas as limitações do presente estudo, observa-se que as linhas mestras das teorias desfraldam a bandeira do humanismo, que já se iniciara com Irnério, voltada para a problemática do homem, como substrato do direito. A noção de dignidade humana passa a comandar a evolução da escola do direito natural à luz da Renascença e do Cristianismo, dentro de um novo sistema jurídico que busca reprimir a opressão, a tirania, o absolutismo, sob a inspiração da idéia de liberdade e igualdade.

Esse movimento reformista do Humanismo no Renascimento abre, entretanto, caminho, a partir do século XVII, para o ingresso de uma doutrina racionalista do direito natural (Naturrecht). Esse direito natural, de índole extremada e radical, denominada jusnaturalismo, não se assemelhava ao direito natural da filosofia greco-romana, conceituado por Aristóteles, ao distinguir o justo por natureza e por lei, principalmente na sua Ética a Nicômaco, como também por Cícero, que fala da lei natural "como a verdadeira lei, a reta razão, conforme a Natureza, em todos inscrita, constante, sempiterna...." Com o jusnaturalismo, idéia extremada do Direito Natural, foi introduzida a autonomia da razão, em que o homem passa a ser o centro do mundo e a natureza o seu objeto. $O$ indivíduo é elevado a categoria de princípio e fim da realidade política e jurídica. 


\section{OS DIREITOS DA PERSONALIDADE NAS LEGISLAÇÕES MODERNAS}

A Bioética vem florescendo como uma "nova ciência", ocupando-se de todas as questões que envolvem os atos de disposição do próprio corpo, tais como a experimentação humana para fins científicos e terapêuticos, a doação de órgãos e tecidos humanos, a inseminação in vitro, a biotecnologia aplicada a Medicina, o aborto, a eutanásia, a recusa de tratamento médico por parte do paciente, "o direito de morrer com dignidade", e todas as demais questōes que envolvem conteúdos valorativos e busca de padrões morais tanto individuais como coletivos.

Como vimos, ao delinearmos as origens dos direitos da personalidade, tais questões, mutatis mutandis, foram objeto de profundas indagações nos séculos XVI e XVII, notadamente com a obra dos pós-glosadores que se espalhou por toda a Europa, disseminando-se entre os pandectistas do século XIX a ponto de influenciar todas as codificações modernas.

O Código Civil Alemão, cuja vigência data de 1900, prevê uma tutela considerada indireta dos direitos da personalidade, que tem por objetivo a proteção da inviolabilidade da pessoa, no campo dos direitos das obrigações, sob a epígrafe dos atos ilícitos, no $\S 823$ : "Quem por dolo ou negligência lesar, antijuridicamente, a vida, o corpo, a saúde, a liberdade, a propriedade ou qualquer outro direito de uma pessoa estará obrigado, para com essa pessoa, à indenização do dano daí resultante". E acrescenta: "Igual obrigação incumbe àquele que infringiu uma lei destinada a proteção de um outro, e, de acordo com o conteúdo da lei, se for possível, mesmo sem culpa, uma infração desta, só caberá a obrigação de indenização no caso de culpa".

Embora seja tímida a proteção dada pelo $B G B$, importa salientar que foi justamente na Alemanha, com os juristas do século XIX, que floresceu a idéia de um direito geral de personalidade e a doutrina farta como se vê em Puchta, que adotou a expressão "direitos da personalidade", Gareis, Kohler, Neuner, Windischeid, Vangerow, que escreveram sobre os chamados "Individualrechte" ou "Personalitätsrechte".

$\mathrm{Na}$ França, a proteção é pretoriana, pois os direitos da personalidade não foram objeto de tratamento específico no Código de Napoleão de 1803.

Considerando que o Direito não se resume na lei, a jurisprudência francesa é uma das mais ricas e abundantes em matéria de direitos da personalidade, na tutela da individualidade física, intelectual, moral e jurídica, ou seja, a proteção da pessoa humana em todos os seus atributos e elementos constitutivos, pois toda a violação aos bens da personalidade faz nascer uma responsabilidade tanto civil quanto penal. 
Por sua vez, o Código Civil italiano, fruto de longa e erudita elaboracão doutrinária, serviu de modelo a muitas legislações ao tratar da pessoa, e traz preceitos preciosos sobre os direitos da personalidade. No seu art. $5^{2}$, que disciplina os atos de disposição do próprio corpo, assim dispõe: "GLI atti di disposizione del proprio corpo sono vietati quando cagionimo una diminuzione permanente della integrita fisica, e quando siano altri menti contrari alla legge, all'ordine pubblico o al buon costume".

É regra geral dos direitos da personalidade que eles não comportam limitação voluntária, isto é, a autonomia privada cede lugar aos preceitos juridicos, aos bons costumes e à ordem pública. Toda ofensa a integridade física, dentro da capacidade de consentir que possa ferir a lei, os bons costumes e a ordem pública, é proibida. Todo contrato que tenha por objeto ato de disposição do próprio corpo e que possa comprometer a integridade é considerado nulo de pleno direito. Como diz Trabucchi, "Il contratto con il quale si dispone di parti unite (naturalmente o per arte) al corpo è nullo: non ammete esecuzione coattiva, nè risarcimento di danni in caso d'inadempimento"(22).

O Código Civil português igualmente cuida especificamente dos direitos da personalidade. Consagra no seu art. 70 a tutela geral da personalidade, prescrevendo: "1. A lei protege os indivíduos contra qualquer ofensa ilicita ou ameaça de ofensa a sua personalidade física ou moral. 2. Independentemente da responsabilidade civil a que haja lugar, a pessoa ameaçada ou ofendida pode requerer as providências adequadas às circunstâncias do caso, com o fim de evitar a consumação da ameaça ou atenuar os efeitos da ofensa já cometida". Por sua vez, 0 art. 81 se refere a limitaçăo voluntária dos direitos da personalidade, como se vê em sua redação: "1. Toda a limitação voluntária ao exercício dos direitos da personalidade é nula, se for contrária aos princípios da ordem pública. 2. A limitação voluntária, quando legal, é sempre revogável, ainda que com obrigação de indenizar os prejuízos causados às legítimas expectativas da outra parte".

Em nosso Direito, que se filia ao sistema romano-germânico, o Código Civil de Beviláqua não traz em sua Parte Geral o tratamento específico da matéria, mas nem por isso os nossos melhores doutrinadores deixam de cuidar da matéria. Grande precursor foi Orlando Gomes, que a colocou em seu Projeto do Código Civil, especificando os direitos da personalidade e assim dispondo em seu art. 28: "Direitos da personalidade - $\mathrm{O}$ direito à vida, à liberdade, à honra, e outros reconhecidos à pessoa humana, são inalienáveis e intransmissiveis, não podendo seu exercício sofrer limitação voluntária". Já, no parágrafo único, dispōe: "Quem for atingido ilicitamente em sua personalidade pode exigir que o atentado cesse e reclamar perdas e danos, sem prejuízo de sanções de outras naturezas a que fique sujeito o ofensor". Em linhas gerais, o Projeto Orlando Gomes, além de dispor sobre 
o direito ao nome, cuida dos atos de disposição sobre o próprio corpo; disposição do cadáver; tratamento médico; exame médico; perícia médica; reprodução da imagem; direitos autorais; etc.

O nosso atual projeto do Código Civil, embora de maneira mais tímida, traz na sua Parte Geral um capítulo dedicado aos Direitos da Personalidade, cumprindo salientar no que tange aos atos de disposição do próprio corpo, aos moldes do Projeto Orlando Gomes e do Código Civil italiano, proíbe a limitação voluntária no exercício dos direitos da personalidade, com a ressalva dos casos previstos em lei. Quanto à integridade física, ou seja, corporal, o art. 13 assim prescreve: "Salvo por exigência médica, é defeso o ato de disposição do próprio corpo, quando importe diminuição permanente da integridade física, ou contrariar os bons costumes". Por sua vez, o art. 15 assim determina: "Ninguém pode ser constrangido a submeter-se, com risco de vida, a tratamento médico ou a intervenção cirúrgica".

Prevendo o Projeto que os direitos da personalidade são intransmissíveis e irrenunciáveis, todo ato, toda a ação calcada na autonomia individual que possa comprometer o bem da personalidade pela sua irrenuniciabilidade revela-se nula de pleno direito.

Obviamente não podemos discorrer aqui sobre todos os aspectos e todas as características dos direitos da personalidade que comportam a sua teoria geral, o que foi objeto de nosso trabalho ao longo de anos ${ }^{(23)}$. Traçadas as linhas mestras, buscamos apenas cotejar o princípio da Bioética, no caso a autonomia aliada ao "consentimento informado", para uma pequena contribuição ante o avanço das ciências, da biotecnologia e da biomedicina, em que os Direitos da Personalidade se fazem cada vez mais presentes; na tutela da integridade física, psíquica, moral e intelectual do ser humano, muitos dos quais são as garantias dos direitos individuais na esfera privada.

Não nos cabe aqui traçar os lindes entre a moral e o direito, entre a deontologia médica e os direitos da personalidade que dizem respeito a integridade corporal. Em suma, não nos compete falar aqui sobre a ética e o direito. Mas, as questões levadas a efeito pela bioética, sem dúvida, revelam-se suportes fáticos concretos, relevantes para a dinâmica dos Direitos da Personalidade, recebendo o seu devido conteúdo jurídico, impondo-se assim a sua retomada e o seu avanço que se faz premente.

\section{CONCLUSÃO}

No momento em que a Bioética erige a autonomia como seu princípio fundamental aliado ao "consentimento informado" de todo o homem racional, faculta-lhe a escolha do tratamento e da terapêutica em face do médico,

(23) Daisy Gogliano, "Direitos Privados..." cit., 1982. 
isto é, o paciente pode escolher o tipo de tratamento entre os que the são oferecidos, tem a faculdade, justamente por ser racional, tanto de rejeitar como de impor a sua vontade individual isolada na relação médico-paciente. Com isso, sob a idéia distorcida de proteção à inviolabilidade e à integridade corporal, tal escolha é racionalista, sob o primado da razão, mesmo que o tratamento e a terapêutica possam comprometer a sua saúde chocam-se com os princípios básicos dos direitos da personalidade.

Tal premissa distancia-se frontalmente daquilo que se considera direito da personalidade, consoante vimos em linhas atrás, calcados inicialmente sob a ótica de um jus in se ispum, na concepção extremada do jusnatularismo, aos moldes do direito de propriedade, em muito se distanciaram dessa concepção individualista que informou o Direito Natural, para um retorno à doutrina clássica do Direito Natural(24).

Olvidam os precursores da autonomia na Bioética, conseqüência do mencionado "consentimento informado", que em matéria de Medicina (a justa medida, a proporcional medida a ser dada a cada qual), o ser humano em face de sua miserabilidade, em face de sua própria condição humana está a se defrontar com a doença $\theta \mathrm{com}$ a morte. Justamente aquilo que mais fragiliza o homem em sua totalidade. Doença e morte é sinônimo de dor, sofrimento, choro, angústia e tempestuoso desequilíbrio. Toda e qualquer higidez mental fragiliza-se ante a doença.

Quando o ser humano, doente ou enfermo, busca a Medicina justamente em apelo, buscando ajuda para os seus padecimentos, para o seu desamparo, para a sua cruel solidão diante do mistério da morte. Busca e apela uma resposta. O médico é por sua arte e sua técnica, o único capaz legitimamente de minorar-Ihe o sofrimento e o padecimento, em ajuda, em solidariedade e em colaboração.

(24) Maria Carolina Soares Guimarāes, Mary Jane Paris Spinke Mitsuko A. M. Antunes. "Do respeito à compreensāo das diferenças: Um othar, sobre a autonomian, in Revista Bioética, Brasília, CFM, 1997, vol, 5, pp. 13-4. Com o devido respeito, discordamos das ilustres autoras quando tratam da autonomia no "Simpósio: A ética da Alocação de Recursos de Saúde", nos seguintes termos: "O respeito pela dignidade da pessoa humana é reafirmado no campo da autonomia do sujeito de pesquisa, e se explicita no processo de obtenção do consentimento esclarecido. Por meio dele, atirma-se que o sujeito é livre para decidir, quando dotado de autonomia plena, que sua decisão deve ser obedecida mesmo quando errada, contrária mesmo aos interesses de saúde ou de outra natureza, seu ou de alguém que ele represente". Esclarecem ainda: "... Há apenas uma norma, o sujeito deve ser respeitado como pessoa humana e, por decorréncia, em suas decisōes. Salvo nos casos de prisioneiros (e mesmo aqui há certo espaço de manobra), sempre que houver capacidade de decisão, ainda que pequena, esta deve ser privilegiada, pois o respeito tem relaçāo com a pessoa humana na sua totalidade, sua razäo e emoções, mesmo que seu estatuto jurídico aponte em outra direção". Tal opinião é quase sedimentada por aqueles que cuidam da Bioétiça, fundada na autônoma do sujeito, no "imperativo categórico" de Kant, razāo pura em conformidade com a razão universal nảo se coaduna mais com o nosso sistema jurídico e político-filosófico. A açāo humana autónoma cede lugar ao agir segundo a norma juridica. Não nos cabe aqui discorrer sobre a ética individual e social em consonância com o Direito. 
Partilha o doente com o médico todo o seu sofrimento diante da doença, busca ajuda, busca amparo do mais precioso. Ao médico, como "expert", o único conhecedor de patologias, como aquele habilitado por sua profissão, é facultada a "arte de curar". Portanto, relegar ao paciente na sua profunda angustia, por mais racional que ele seja, decidir sobre o seu próprio destino é ferir comezinhos princípios jurídicos. Buscar o racionalismo abstrato e eidético diante da dor e do sofrimento advindos da doença, em face de debilidade do próprio paciente é deixá-lo na mais completa derelição.

Não se pode oferecer ao paciente, com base no "consentimento informado", tal qual um cardápio, um rol de sugestões de curas plausiveis, abandonando-o à sua livre escolha, para que decida, isto é, para que se auto-determine, no momento em que a procura de um profissional legitimamente habilitado justifique tal conduta humana.

Relegar o paciente, com base na autonomia, para que ele possa decidir livremente mesmo contra a saúde (categoria), abandonando-o à sua própria sorte quando ele apela ao outro, pode resvalar a omissão dolosa de socorro médico. Tal fato por certo não passará despercebido aos Juristas, pois não é dado ao médico dar "meia Medicina", em razão de sua própria profissão que não pode ser descurada.

Não se pode, v. g., com base na autonomia, deixar ao paciente a escoIha sobre a espécie de tratamento ou terapêutica a ser ministrada quando necessite de quimioterapia, cirurgia ou radiação, o que importará em maior angústia e aflição, podendo, isto sim, causar-Ihe danos morais como materiais, na violação aos direitos da personalidade que não comportam limitação voluntária. Olvidando os direitos do paciente, a autonomia vem, isto sim, redundar em ditadura, sob pseudo liberdade.

Ademais disto, no campo do direito civil, a relação médico-paciente está, na maioria das vezes, calcada em um contrato, ou seja, na prestação de serviços médicos de saúde, quando não esteja sob a égide do Código de Defesa do Consumidor, no qual o paciente é considerado hiposuficiente, devendo, por conseguinte, o prestador de serviços médico-odontólogicos estar obrigado por lei a proteger os direitos básicos do consumidor alinhados nos arts. $6^{\circ}$ e $7^{9}$ da Lei n. 8.078 de $11 / 9 / 90$, com especial realce a "proteção da vida, saúde e segurança contra os riscos provocados por práticas no fornecimento de produtos e serviços considerados perigosos ou nocivos". A informação adequada e clara sobre os diferentes produtos e serviços a serem fornecidos ao consumidor de serviços de saúde não envolve, sob hipótese alguma, o abandono a sua "autonomia", eis que o Código de Defesa do Consumidor é claro quando determina em seu art. $7^{\circ} 0$ respeito aos direitos derivados dos princípios gerais do direito, da analogia, costume e eqüidade.

Ora, o prestador de serviços de saúde não pode se eximir de "dar a cada um o que é seu", com base nos princípios primeiros de justiça, onde 
em matéria de Medicina sobreleva o nenimen laedere, pois "não lesar ninguém é princípio ético de Justiça".

Por outro lado, quando se busca um profissional da Medicina este não pode se eximir, à guisa de respeito a autonomia, de dar a Medicina adequada e proporcional ao paciente, a sua justa medida, sob pena de inexecução culposa do contrato e responsabilidade de perdas e danos.

O fato é que a idéia de "autonomia" vem sendo desvirtuada a tal ponto que a inexecução contratual está sendo propalada sem maiores indagações, pois sustentar a autonomia do homem como ser racional não implica, sobre hipótese alguma, deixar de the reconhecer os seus direitos como paciente, ou seja, o direito ao exame médico especializado, ao diagnóstico de sua doença, ao tratamento e terapêutica que a própria Medicina fornece e coloca a serviço de sua cura, considerando-se a obrigação do médico como meio ou resultado, em face do caso concreto; a condução técnica do tratamento é de exclusiva responsabilidade do médico, que não pode deixar de se furtar a ministrar os cuidados que a sua arte e a sua ciência colocam a serviço. E a quem compete por lei e por direito prestar serviços médicos em sua inteireza.

O médico atua tendo por princípio as bases da propedêutica e da semiologia médica, diante das quais não pode descurar, sob pena de não dar Medicina. A relação médico-paciente funda-se na mútua confiança, no diálogo, na maiêutica Socrática, que faz revelar a doença e os meios de cura, vale dizer, de cuidado e de desvelo.

Importa observar no presente estudo, não obstante suas limitações que não permitem digressões mais aprofundadas, que a autonomia tal como proposta, de origem "kantiana", desenvolveu-se principalmente nos Estados Unidos da América com o estudo da Bioética. Tais idéias floresceram sobretudo nos paises do sistema da common law, notadamente costumeiro, o que em hipótese alguma se coaduna com o nosso sistema jurídico, da família romano-germânica, em que a lei é fonte ou forma principal de expressão do direito. Não compartilhamos do sistema não-escrito, aberto, em que as decisões jurisprudenciais constroem o Direito posto, pois, entre nós, dada a origem européia de nosso direito, a jurisprudência contra legem não é admitida em face do seu papel vivificador da leí.

Como em matéria de Medicina os pesquisadores e estudiosos, em sua maioria, encontram na literatura norte-americana toda a sua fonte de inspiração, toda a base de sua ciência, eis que estudar medicina está se tornando sinônimo de estudar a medicina norte-americana, na sua supremacia, o conflito não se faz esperar ao deduzirem que os juristas deste pais são filiados às decisões norte-americanas, a ponto de propugnarem por uma construção jurisprudencial toda impregnada dos princípios da common law.

Ora, nosso sistema juridico não se compadece com as doutrinas alienígenas fundadas na common law, dada a índole romano-germânica do di- 
reito brasileiro, por inexistir qualquer similitude, alheia às nossas tradições jurídicas.

Por sua vez, admitindo-se na common law a exoneração de responsabilidade do médico em face do "consentimento informado" e da autonomia, pois estando ciente o paciente dos riscos do tratamento e da terapêutica a ser-lhe ministrada, não poderá imputar ao médico desídia na sua profissão, tal fato, em nosso direito, em tempo algum terá o condão de exoneração de responsabilidade, em matéria de cláusula de não-indenizar. Se o direito à integridade física, como direito da personalidade ou direito da pessoa humana, não comporta limitação voluntária, contratual, sendo ainda irrenunciável e intransmissivel, justamente dado o seu caráter absoluto, erga omnes, toda e qualquer exoneração de responsabilidade feita pelo paciente revela-se nula de pleno direito, principalmente diante dos preceitos do Código de Defesa do Consumidor, cujos direitos básicos não podem ser feridos.

Por aí se vê a incoerência e a contradição em que caem aqueles que tentam impor ao nosso sistema juridicos idéias alienígenas, que não podem ser em hipótese alguma agasalhadas, em violação as nossas mais sagradas tradições, que envolvem séculos e séculos de Ciência Jurídica.

Incorrem em nítida má-fé aqueles que com base na "autonomia" relegam o paciente a sua exclusiva vontade, deixando ao seu arbítrio a escolha do tratamento adequado, sem resposta às suas indagações. Muitas vezes diante do progresso médico, dos recursos tećnológicos postos à disposição, das pesquisas médicas levadas a efeito sobre determinada patologia, a ponderação quanto ao tratamento é discutida livremente entre o médico e o paciente ou entre o médico e sua família, medindo e pesando os prós e contras, na abertura do diálogo, isto é, o médico "sendo" o paciente, empre. gando aqui a expressão de Martin Heiddegger.

que não se concebe, em termos de responsabilidade profissional e técnica, é a atuação do médico sob as ordens do paciente ou sob a sua livre escolha, com respeito à autonomia, cabendo ao profissional recusar a contratação, por justa causa, alentando comprovadamente o paciente sobre os riscos de sua decisão.

lludem-se os profissionais que julgam exonerar-se de responsabilidade pelo simples fato de o paciente preencher formulários, termos de responsabilidade e todas as demais fichas e papéis burocráticos na contratação, em face de prestações determinadas, mesmo estando o paciente ciente dos riscos. A saúde é matéria de ordem pública que não comporta violação por pacto particular. Não é sem razão, como discorremos anteriormente, que os direitos personalíssimos estão sob o crivo da ordem pública dos bons costumes, daquele ethos que informa toda a sociedade. 
Caio Mário da Silva Pereira, ao lecionar sobre a aceitação da cláusula de não indenizar, revela a sua proibição em afronta aos princípios de ordem pública e contra os bons costumes e a boa-fé - contra bonam fidem contraque bonos mores (cf. Mazeaud e Mazeaud, "Responsabilité Civile", vol. III, n. 2.525; Planiol Ripert e Esmein, "Traité Pratique de Droit Civil", vol. VI, pp. 405 e ss.; Giuseppe Manca, "Pactum de dolo non preasstanto", in Dizionario de Scialoja; Yves Chartier, "La Reparation du Préjudice", n. 490, p. 605), dada a sua aplicação restrita em nosso direito, como no caso em que seria injurídico nos casos em que a pessoa não tem a liberdade de deixar de contratar fosse adstrita a aceitar uma convenção contrária a seus interesses, sob fundamento de que o serviço foi "livremente aceito"(25), tal como sucede, v.g., nos "termos de responsabilidade" dos hospitais adrede preparados e submetidos ao paciente que, obviamente, por necessidade de serviços médicos não pode discutir livremente as suas cláusulas.

Por outro lado, a tão falada autonomia cede lugar ante o estado de necessidade quando o médico deve prestar atendimento mesmo contra a vontade do paciente.

Muitos não percebem que a "autonomia" surge no momento em que as pessoas tomam consciência de seus direitos individuais, da sua cidadania, buscando cada vez mais acesso ao Poder Judiciário na tutela dos seus direitos, em que as indenizações, principalmente nos Estados Unidos da América, assumem valores vultosos, caminhando pari e passu com a dessacralização da Medicina, com a prestação de serviços de massa e proletarização do médico, com a inclusão do conventio de dolo non praestando, ou como diz Caio Mário, a cláusula que é inidônea para eximir o devedor dos efeitos de seu procedimento doloso", no caso, o prestador de serviços médicos, que por sua habilidade e capacidade técnica, não pode com base na "autonomia" se eximir daquilo que sabe causar dano.

Enquanto a Medicina caminha imbuída de conceitos norte-americanos, lastreados na common law, o que não é nenhum desdouro notadamente por se tratar de ciência médica em que a tecnologia assume papel cada vez mais preponderante, o Direito, por sua vez, em nosso país, aglutina-se ao redor dos princípios romano-germânicos, em flagrante colisão de interesses que só redundam na desarmonia, que passa a presidir a relação médico-paciente.

Tal distanciamento é explicado pela Professora Ricardina Giovanna Pitelli da Guia, em sua Dissertação de Mestrado apresentada a Faculdade de Saúde Pública da Universidade de São Paulo, sob a denominação de "O Elo Partido - O Relacionamento Médico-Paciente na Era Tecnológica”, com a

(25) Caio Mário da Silva Pereira, “Responsabilidade Civil”, $3^{a}$ ed. rev. e atualizada, Rio de Janeiro, Forense, 1992, n. 245. 
obtenção de aprovação com louvor pela douta banca examinadora, em contribuição inestimável, ao demonstrar a repercussão da prática médica norteamericana em nosso país: As práticas médicas executadas no Brasil até o início do século espelhavam-se profundamente na medicina européia por dois principais motivos: a origem de nosso processo de colonização e o fato de se constituir a medicina européia, até então, a condutora do pensamento e da prática médica ocidental. No entanto, o capitalismo, ascendente na primeira metade deste século, traz uma nova e poderosa influência sobre a sociedade ocidental, a qual foi particularmente importante para o Brasil: a ascensão dos Estados Unidos da América como nova potência mundial. Assim, principalmente a partir da Segunda Grande Guerra Mundial, a medicina brasileira, que se orientava por princípios valorizados na Europa, passa a ser cada vez mais determinada pelo caminhar da medicina norte-americana. No entanto, a incorporação do que podemos denominar "modelo norte-americano na prática médica brasileira não se constitui em uma ocorrência isolada, inserindo-se em profundas mudanças na ordem econômica mundial...". E acrescenta: "...cada vez mais as escolas de medicina se libertam da influência da medicina européia e espelham sua atividade docente e acadêmica na medicina norte-americana, iniciando-se ai a tendência, que persiste até os nossos dias, de servirmo-nos das instituições daquele país como palco de treinamento para nossos profissionais de saúde, fossem eles médicos, enfermeiros ou outros quaisquer. Tal influência refletiu-se não apenas nas práticas e valores de que nossa medicina se serviu, como teve profundos reflexos na forma como se organizaram nossos serviços de saúde"(26).

No campo filosófico, cumpre tecer pequenas considerações. No momento em que a Bioética coloca a autonomia do sujeito como seu fundamento e seu princípio, por ser o homem o ser racional, deixa de compreendê-lo em sua totalidade, em sua essência mais profunda, como ser dotado de "humanistas", não só como aquele que quer e decide, como aquele que se auto-determina, como aquele que sofre, que chora, que sente e se angustia. Essa visualizacão fragmentada do ser humano, reflete-se sobretudo nos atos que envolvem a prática médica, no agir, na ação humana, em que o sensivel resta esmagado pelo intelegivel. E o ser humano completamente desvinculado da existência e da experiência.

Um grande filósofo da atualidade Michel Meyer, tecendo críticas é filosofias de Kant, em sua magnífica obra "O Filósofo e as Paixões - Esboço de uma História da Natureza Humana", demonstra com a clareza que Ihe é peculiar em todos os seus escritos: "...É certo que Kant postula a existência de uma realidade humana fora da natureza, que coloca os homens fora de si

(26) Ricardina Giovanna Pitelli da Guia, "O Elo Partido - O Relacionamento Médico-Paciente na Era Tecnológica", Dissertação de Mestrado, São Paulo, Faculdade de Saúde Pública - USP, 1995, pp. $101 / 102$. 
mesmos, no universal abstrato, sem paixão, mas não pode negar a natureza sensivel e particular do humano, que também o caracteriza. Esta humanidade vazia, absolutamente metafísica, que deve servir de base à ação e que alimenta a reflexão, a ponto de nela desenvolver o prazer estético, dificilmente poderá resistir à temível questão da sua própria realidade ou até da sua instauração a um nível diferente do ideal e formal"(27).

Ora, no momento em que esta filosofia, que vem impregando a Bioética, de caráter utilitarista, busca o primado da razão, do imperativo categórico está a sustentar um caráter apriorístico de uma moral universal, alijando completamente a moral social, a moral familiar e a moral de uma coletividade, o éthos, ou seja, a tradição.

Mais grave se torna ainda, na área biomédica, quando o "pathos" participa da natureza humana. Ou como diz Meyer. "No fundo, razão sem paixão não é mais do que ruína da alma"(28). Negar o "pathos" é niilismo, porque não podemos separar o homem de sua essência, da sua existência, da sua vivência, das suas emoções. Tanto a calma exacerbada como a razão desenfreada revelam-se perigosas. Como, igualmente, não se pode negar o fato social sobre o qual repousa o Direito, na constituição do fato jurídico, como vimos no início do presente estudo.

O racionalismo da Bioética descarta tanto a natureza humana quanto a própria natureza em si. Essa determinação buscada pela Bioética revelase ilusória, sob o manto de uma possivel "razão pura", pois, como vimos, os direitos da personalidade no seu exercício podem ser revogados, e os vícios do consentimento ou da vontade podem acarretar a anulação do ato jurídico, por erro, dolo, coação, fraude ou simulação.

O que são os vícios ou defeitos do consentimento, que ensejam a anulação do ato de vontade ou de uma declaração de vontade nos negócios jurídicos senão a prova de que o primado da razão não pode ter lugar no Direito? Por exemplo: Um ato sob coação, que possa viciar toda e qualquer manifestação de vontade, por fundado temor de dano à sua pessoa, à sua família, ou a seus bens, na forma preconizada pelo art. 98 do Código Civil, terá seus efeitos coarctados.

Ao apreciar a coação, determina o art. 99 do Código Civil Brasileiro que dever-se-á ter em conta "o sexo, a idade, a condição, a saúde, o temperamento do paciente e todas as demais circunstâncias que the possam influir na gravidade", nada mais consoante a natureza das coisas do que o preceito em vigor.

(27) Michel Meyer, "O Filósofo e as Paixōes - Esboço de uma História da Natureza Humana", trad. Sandra Fitas, Porto, 1994, p. 222.

(28) Idem, p. 10. 
Dizer-se autônomo na regulação dos próprios interesses não é ser livre como possa parecer à primeira vista. Como também, não se pode fazer com que uma moral individual e particular possa ser universalizável, colocando-se o sujeito como espectador da sua própria natureza, em consciência reflexiva, ou seja, na superação da sua própria natureza, ou "ir além daquilo que the é natural"(29). Nada mais paradoxal.

Observa Meyer com muita propriedade: "Se virmos bem, a liberdade e a necessidade são o reverso de uma mesma realidade. Se digo que sou livre de fumar ou de deixar de o fazer, esse juízo não é mais verdadeiro do que aquele que afirma: estou determinado a fumar porque este ou aquele fator me levaram a isso, mesmo quando julgo que sou livre para continuar (ou deixar) e este juízo resulta também de fatores que me levaram a crer nele e a afirmá-lo. Do mesmo modo, se deixasse de fumar, poderia julgar estar a praticar um ato de liberdade, embora na realidade várias coisas me tivessem condicionado a fazê-lo e a pensar o contrário, levando-me a dizer e a pensar que era livre. A liberdade de deixar de fumar torna-se assim uma ilusão, que consiste em considerar como uma decisão espontânea da minha parte aquilo que não é mais do que o resultado de um conjunto de fatores numa longa cadeia causal. Julgar-me e afirmar-me livre, assim como agir, resultam também de fatores, de que não terei talvez consciência, mas que sāo perfeitamente reais" ${ }^{\prime(30)}$.

O mesmo se aplica em Medicina, nas ocasiões em que por força das próprias circunstâncias da doença o paciente seja obrigado a suportar tratamento e terapêutica incômodas e dolorosas, deixar de o fazer, mesmo envolvido no processo da doença, não é ser mais livre, pois a doença - precisamente por não ser o reverso da saúde no ensinamento de Aristóteles não é um processo alheio ao paciente.

Afirmando Kant uma liberdade para lá da natureza, mantém a questão, como leciona Meyer, de saber "como é que um ser guiado pelos seus afetos e paixões, pelos seus desejos e interesses pode ser levado a renunciar-Ihes por razões morais, de auto-determinação. É certo que a autonomia da vontade exprime essa possibilidade (metafísica) de realizar o dever, mas ela é extremamente hipotética. Se a moralidade é possível como aplicação das normas vindas da parte inteligivel ou intelectual da realidade humana, que escapa ao determinismo e pode, assim, impor a sua própria lei de ação, isso não impede que o homem tenha uma parte sensivel que é uma fonte de múltiplos prazeres e interesses pessoais a que ele dificilmente renuncia, como nos mostra a experiência. Desse modo, não está ele então a agir também de acordo com a sua natureza, a não ser que se considere pertencente a sua

(29) Michel Meyer, "O Filósofo..." cit., p. 222.

(30) Idem. Ibidem. 
natureza não ter uma natureza própria? O que é paradoxal, tanto mais que a transformação da vontade numa vontade moral surge como algo incompreensivel. A moral não é mais do que um puro dado metafísico"(31).

O IV Congresso mundial de Bioética realizado em Tóquio, 4-7 de novembro de 1998, organizado pela associação Internacional de Bioética, recebeu críticas sobre o universalismo dos princípios fundamentais da Bioética, principalmente a autonomia, ao lado do princípio da beneficência, justiça e eqüidade, calcada sob a "tirania do racionalismo". Esse individualismo extremado, típico do iluminismo, vale dizer, nas palavras do ilustre presidente do Congresso, Professor Hyakudai Sakamoto, sem levar em conta o ecossistema ao lado de um "antropocentrismo obsessivo", deve ser abandonado, sustentando que se impõe salvaguardar a HARMONIA, abandonando a mentalidade tipica de Far West (frontier mentality) ${ }^{(32)}$.

Sublinhando a importância da harmonia dentro do pensamento oriental: harmonia que cobre as relações do ser humano no quadro de sua família, com seus semelhantes e a sociedade em geral, com os animais e a natureza, onde tais princípios não levam em conta os interesses da comunidade e ainda da saúde pública(33).

Os comentários ao IV Congresso Internacional de Bioética foram feitos pelo Prof. Jean Martin, médico do serviço de saúde pública, do cantão de Vaud, Suíça, e docente na Faculdade de Medicina da Universidade de Lausanne, demonstrando a necessidade de um relativismo ético.

A nossa pequena e modesta contribuição com o presente trabalho é justamente contribuir para esse relativismo que se faz necessário, eis que os fundamentos da Bioética, tal como se apresentam, têm sido alardeados sem maiores reflexões, como verdadeiros "slogans", repetidos em quase todos os estudos sobre a matéria. Na verdade, muito ficou por ser dito, diante das posições políticas e ideológicas que informam os princípios da Bioética em colisão com os direitos personalíssimos.

Finalizamos com a lição sempre cunhada pelo Professor Aloysio Ferraz Ferreira: "O Direito é o mínimo ético".

(31) Michel Meyer, "O Filósofo..." cit., p. 213.

(32) Jean Martin, "Recueil Intern. de L. Sanitaire", O. M. S., 1999, v. 50, n. 2, p. 293.

(33) Idem, ibidem. 